\title{
Influence of nitrogen configuration on the electrochemical properties of carbonized poly(acrylonitrile)-ionic liquid as anode materials in lithium ion batteries
}

\author{
Lei Wang ${ }^{1}$, YAnshuang Meng ${ }^{1}$, Mengqi Du $^{1}$, Gongrui Wang $^{1}$, Jun XiA ${ }^{1}$, \\ FULiANG ZHU ${ }^{1,3, *}$, YUe ZHANG ${ }^{2}$ \\ ${ }^{1}$ School of Materials Science and Engineering, Lanzhou University of Technology, Lanzhou 730050, China \\ ${ }^{2}$ Department of Mechanical and Industrial Engineering, Texas A\&M University-Kingsville, Kingsville, Texas, 78363, USA \\ ${ }^{3}$ State Key Laboratory of Advanced Processing and Recycling of Non-ferrous Metals, Lanzhou 730050, China \\ A sequence of $\mathrm{N}$-doped carbon materials has been synthesized using poly(acrylonitrile)-ionic liquid copolymers as carbon \\ precursors. The nitrogen content and configuration in carbon materials has been changed regularly within a certain range by \\ adjusting the proportion of ionic liquids. We found that the capacity and rate performance increased dramatically after the \\ introduction of ionic liquids, which was attributed to incorporation of higher amount pyridinic-N, pyrrolic- $\mathrm{N}$ into the carbon \\ materials. Besides, with the increase of the graphitic-N, the initial Coulombic efficiency decreased from $58.5 \%$ to $53.47 \%$ and \\ the $\mathrm{R}_{\mathrm{SEI}}$ raised from $66.34 \Omega$ to $140.96 \Omega$, which was attributed to the higher cohesive energy of Li dimmer than adsorption \\ energy of graphitic-N with $\mathrm{Li}$, since more lithium clusters during the formation of SEI film were formed. The electrochemical \\ tests also revealed the negative role of graphitic- $\mathrm{N}$ in the capacity. Therefore, this work provides a feasible method to design \\ the nitrogen content and configuration of the $\mathrm{N}$-doped carbon materials.
}

Keywords: graphitic-N; poly(acrylonitrile)-ionic liquid copolymers; carbon materials; lithium ion batteries

\section{Introduction}

In the past two decades, rechargeable lithium ion batteries (LIBs) have gradually became the first choice of power sources for portable electronic devices due to their numerous beneficial features [1-4]. Previous studies revealed that the electrochemical properties of LIBs mainly rely on the constituent materials, particularly the anode material [5]. Graphite materials are the commonly used anode materials for commercial LIBs due to their high Coulombic efficiency, outstanding cycling performance and small volume expansion [6-8]. Nevertheless, the low capacity (theoretical capacity is $372 \mathrm{mAh} \cdot \mathrm{g}^{-1}$ ) and rate performance limited the development and applications of LIBs [9]. Many methods have been investigated to improve the performance of graphite materials and among them doping heteroatoms $(\mathrm{B}, \mathrm{P}, \mathrm{N}$, etc.) into

*E-mail: chzfl@126.com carbonaceous material have attracted numerous interests recently [10-15]. Among all these different kinds of heteroatoms, $\mathrm{N}$ is paid the highest attention owning to its small atoms size and high electronegativity $(\chi=3.04)$ which could enhance capacity and rate capacity of carbon materials $[3,16]$. Incorporating $\mathrm{N}$ atoms into carbon framework is an effective way to generate a strong electron donor conductive material near the Fermi level, reduce the band gap, and increase conductivity [17-19].

There are many nitrogen configurations in carbon materials such as pyridinic-N, pyrrolic-N, and graphitic-N connected with $\mathrm{sp}^{2}$ hybridization carbon, etc. Previous studies have shown that different types of nitrogen dopant have different effect on the electrochemical properties of carbon anode in LIBs. The research carried by Chen et al. [20] found that nitrogen doped at the edges of carbon based material can significantly enhance the capacity of LIBs due to the high adsorption energy. Zhu et al. [21] reported that the pyridinic-N and 
pyrrolic- $\mathrm{N}$ can create a large volume of meso- and macro- pores by generating defects in carbon and maintain high adsorption energy, both of which are beneficial to enhance the capacity of LIBs. On the contrary, the nitrile group in carbon materials is detrimental to the capacity of LIBs, and can be transformed into other nitrogen configurations at high temperature, such as pyridinic-N, graphitic-N etc. $[22,23]$. There have been a large number of studies on the effect of graphitic-N on the electrical conductivity of anode materials [24-27]. Besides, a few investigations have shown the negative effect of graphitic-N on the capacity of carbon materials by the first principles calculation [17, 28]. Among various kinds of precursors for nitrogen doped carbon material, polyacrylonitrile (PAN) is an excellent material due to the high carbon residue and high nitrogen content [29]. Besides, poly(ionic liquid)s (PILs) as a carbon source also draws strong interests due to high nitrogen content and easy processability [30]. Therefore, the copolymerization of acrylonitrile and ionic liquid is a good alternative for the design of nitrogen configuration in carbon materials.

In this work, poly(acrylonitrile)-ionic liquid copolymers have been synthesized using ILs and acrylonitrile (AN) as monomer through radical polymerization. Firstly, the addition of a small amount of ionic liquid results in a significant increase of nitrogen content and the electrochemical performance of the carbon material. Secondly, the characterization results indicate that the content of ILs in copolymer plays a critical role in determining the nitrogen configuration in the carbon materials. The test results show that the enhanced capacity is mainly due to abundant defects provided by pyridinic-N and pyrrolic-N. We also found that the higher content of graphitic-N results in increasing ILs monomers, reducing the Coulombic efficiency of initial charge and discharge, increasing the resistance of the SEI film, suggesting that graphitic-N has a negative impact on the capacity of LIBs.

\subsection{Materials synthesis}

The ionic liquid, 1-vinyl-3-ethylimidazolium tetrafluoroborate $\left([\mathrm{VEIm}] \mathrm{BF}_{4}\right)$, was purchased from Lanzhou Institute of Chemical Physics and all the other reagents were obtained from Aladdin (China). All the reagents were of analytical grade and used without further purification. At first, ethanol absolute and distilled water were mixed at a weight ratio of 1:1.4 in a $150 \mathrm{ml}$ flask. The AN and $\left[\right.$ VEIm] $\mathrm{BF}_{4}$ were used as monomer and mixed in the former ethanol solution at different weight ratios (100:0, 95:5, 90:10, and 85:15). The 2,2-azobis (2-isobutyronitrile) (AIBN) and poly(ethylene glycol) diacrylate (PEGDA) were used as initiator and crosslinker, respectively. The polymerization was carried out at $65{ }^{\circ} \mathrm{C}$ with vigorous stirring in argon atmosphere for 15 hours. Then the copolymers were filtrated, washed with ethanol absolute and collected after drying in air at $80{ }^{\circ} \mathrm{C}$ for 24 hours. In the carbonization process, the obtained copolymers were first heated to $250{ }^{\circ} \mathrm{C}$ in air and kept for 4 hours. The materials were further heated to $900{ }^{\circ} \mathrm{C}$ in $\mathrm{N}_{2}$ atmosphere and kept for 2 hours, providing the $\mathrm{N}$-doped carbon. For the monomers mixed at different weight ratios (100:0, 95:5, 90:10, and 85:15), their copolymers were denoted as P0, P5, P10, and P15, respectively; and their N-doped carbon materials were denoted as NCP0, NCP5, NCP10, and NCP15, respectively.

\subsection{Materials characterization}

The thermogravimetric analysis and differential scanning calorimetry (TG/DSC) tests were carried out using the DSC 200F3 thermal analyzer at a ramp rate of $10{ }^{\circ} \mathrm{C} / \mathrm{min}$ in $\mathrm{N}_{2}$ atmosphere. The X-ray powder diffraction (XRD) patterns were collected by a D/max-2400 diffraction system in a 2-theta range of $10{ }^{\circ} \mathrm{C}$ to $80^{\circ} \mathrm{C}(\mathrm{CuK} \alpha$, $\lambda=0.15406 \mathrm{~nm})$. The X-ray photoelectron spectroscopy (XPS) measurements were performed on ESCALAB 250Xi equipped with an aluminum target $\mathrm{X}$-ray source $(\mathrm{AlK} \alpha, 1486.6 \mathrm{eV})$.

\subsection{Electrochemical measurements}

The electrochemical performances of the $\mathrm{N}$-doped carbon materials were tested in CR2032 type half cells, which were assembled in an argonfilled glove box. The coating slurry was prepared using active materials, acetylene black, and 
polyvinylidene fluoride (PVDF) with a mass ratio of $8: 1: 1$. The slurry was dissolved in N-methyl-2pyrrolidone (NMP), coated on a copper foil and dried in vacuum for 12 hours at $80{ }^{\circ} \mathrm{C}$. The CR2032 type half cells were fabricated with Celgard membrane (Celgard 2400) and Li metal foils as counter electrode. The electrolyte was prepared using $1 \mathrm{M}$ LiPF6 in a mixture of ethylene carbonate (EC) and 1,2-dimethoxyethane (DMC) with equal volume. The cycling properties and rate performance were measured by a LAND CT2001A instrument in the voltage range of $0.005 \mathrm{~V}$ to $3.0 \mathrm{~V}$. The cyclic voltammetry (CV) curves and electrochemical impedance spectroscopy (EIS) were measured using CHI 660D electrochemical workstation. The $\mathrm{CV}$ curves were tested at a scanning rate of $0.1 \mathrm{mV} \cdot \mathrm{s}^{-1}$ in the voltage range of $0.005 \mathrm{~V}$ to $3.0 \mathrm{~V}$ and the EIS tests were performed within the frequency range of $0.01 \mathrm{~Hz}$ to $10^{5} \mathrm{~Hz}$.
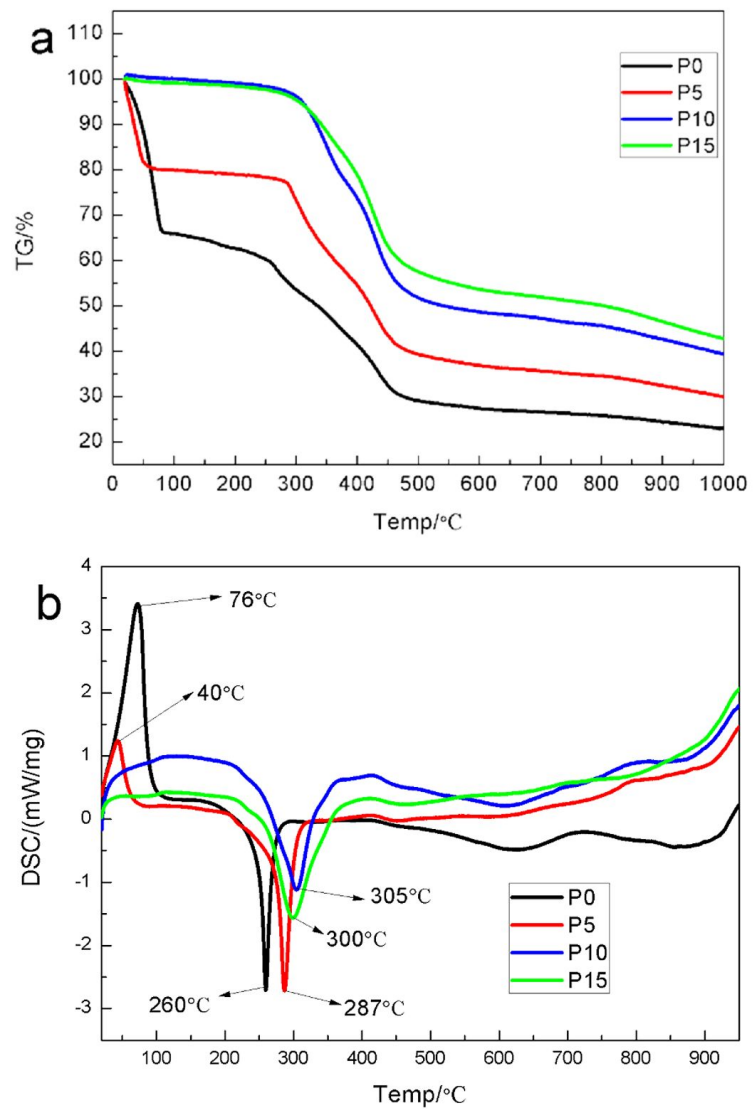

Fig. 1. TG (a) and DSC (b) curves of P0, P5, P10, P15, and $\mathrm{P} 20$ in $\mathrm{N}_{2}$.

\section{Results and discussion}

Since the structure of carbon materials is significantly affected by the carbonization process, the thermal analysis of the carbon precursors was performed. As shown in Fig. 1a, the weight losses of samples prior to $100{ }^{\circ} \mathrm{C}$ are mainly due to the loss of crystalline water inside. Cyclization process took place from $100{ }^{\circ} \mathrm{C}$ to $300{ }^{\circ} \mathrm{C}$. The weight losses of the samples between $300{ }^{\circ} \mathrm{C}$ and $450{ }^{\circ} \mathrm{C}$ were attributed to the volatilization of uncyclized parts. And the weight losses over $450{ }^{\circ} \mathrm{C}$ were attributed the removal of heteroatom compounds [31]. Carbon residues in P0, P5, P10 and P15 differ significantly. The weight percentage of carbon residue increases as the weight percentage of ILs monomers increases in the copolymer, which may be due to the selection and composition during carbonizing process of the co-polymers [32]. As shown in Fig. 1b, each sample exhibits an obvious exothermal peak between $180{ }^{\circ} \mathrm{C}$ and $300{ }^{\circ} \mathrm{C}$, which can be attributed to the cyclization reaction [33]. This exothermal peak becomes wider as more ILs monomer is used in the polymerization process, indicating that ILs monomers can weaken exothermic reaction and improve the controllability of cyclization process. The initial and end exothermic temperature, peak temperature, and the enthalpy change of all the samples, exhibited in Table 1 , show an upward trend, which may be due to increasing nitrogen content in the copolymer which could increase the interaction between nitrogen and carbon atoms.

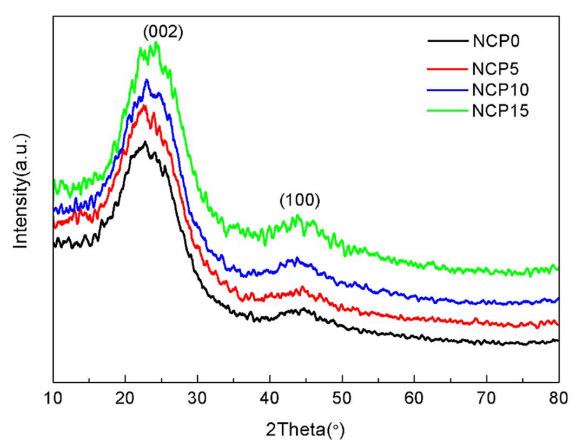

Fig. 2. XRD patterns of NCP0, NCP5, NCP10, and NCP15. 
Table 1. The comparison of TG/DSC data of P0, P5, P10 and P15.

\begin{tabular}{cccccc}
\hline Sample & $\begin{array}{c}\text { Initial } \\
\text { exothermic } \\
\text { temperature } \\
{\left[{ }^{\circ} \mathrm{C}\right]}\end{array}$ & $\begin{array}{c}\text { End } \\
\text { exothermic } \\
\text { temperature } \\
{\left[{ }^{\circ} \mathrm{C}\right]}\end{array}$ & $\begin{array}{c}\text { Peak } \\
\text { temperature } \\
{\left[{ }^{\circ} \mathrm{C}\right]}\end{array}$ & $\begin{array}{c}\text { Temperature range } \\
\text { between initial and } \\
\text { end exothermic } \\
\text { temperature }\left[{ }^{\circ} \mathrm{C}\right]\end{array}$ & $\Delta \mathrm{H} / \mathrm{J} \cdot \mathrm{g}^{-1}$ \\
\hline \hline P0 & 180.9 & 288.7 & 260 & 107.8 & 52.84 \\
P5 & 210.2 & 325.1 & 287 & 114.9 & 65.75 \\
P10 & 205.0 & 381.7 & 305 & 176.7 & 108.2 \\
P15 & 212.8 & 401.0 & 300 & 188.2 & 119.47 \\
\hline
\end{tabular}

Fig. 2 shows the XRD patterns of the carbonized materials. The carbonized materials exhibit two wide peaks at $22.9^{\circ}$ and $44.1^{\circ}$ corresponding to the $\left(\begin{array}{lll}0 & 0 & 2\end{array}\right)$ and $\left(\begin{array}{lll}1 & 0 & 0\end{array}\right)$ planes of graphite, respectively [3]. The $\mathrm{d}\left(\begin{array}{lll}0 & 0 & 2\end{array}\right)$ value remains larger than that of graphite [17]. This larger interplanar spacing is beneficial for $\mathrm{Li}^{+}$intercalation and deintercalation.

To understand the elements content and binding configuration of the carbonized materials, the XPS measurement of NCP samples was performed. The total XPS spectrum (Fig. 3a) shows three peaks at $531.97 \mathrm{eV}, 398.09 \mathrm{eV}$ and $285.46 \mathrm{eV}$, which are ascribed to O1s, N1s and C1s, respectively [34]. The intensity of N1s peak is strengthened with the increase of ILs monomer ratio, which is due to the imidazole ring of ILs containing two nitrogen atoms. The C1s spectra of all samples (Fig. $3 b$ to Fig. 3e) exhibit the deconvoluted peak for $\mathrm{C}-\mathrm{C}$ or $\mathrm{C}=\mathrm{C}(284.6 \mathrm{eV}), \mathrm{C}=\mathrm{N}(285.7 \mathrm{eV})$ as well as the overlap of C-O and C-N (286.6 eV) [35]. The N1s spectra of all samples (Fig. 3f to Fig. 3i) are deconvoluted into three peaks centered at $398.4 \mathrm{eV}$, $400.3 \mathrm{eV}$ and $401.3 \mathrm{eV}$, which are ascribed to pyridinic-N, pyrrolic-N and graphitic-N, respectively [36]. The fitting results of different binding configurations are listed in Table 2 . The content of graphitic-N and the ratio of graphitic-N to total nitrogen both show an obviously upward trend with the increase of ILs monomer ratio and the variation trend of $\mathrm{C}-\mathrm{N}$ also confirms these changes, which could contribute to the electrical conductivity of the carbonized materials [37]. Moreover, the pyridinic$\mathrm{N}$ and pyrrolic-N contents also show upward trend in addition to NCP10, which could contribute to the reversible capacity of LIBs [27].
Fig. 4a shows the first galvanostatic chargedischarge cycle of NCP0, NCP5, NCP10, and $\mathrm{NCP} 15$ at a current density of $37.2 \mathrm{~mA} \cdot \mathrm{g}^{-1}$. All samples exhibit similar voltage profiles in the range of $0 \mathrm{~V}$ to $3 \mathrm{~V}$. The discharge platform and the charge capacity are mainly concentrated between $0.005 \mathrm{~V}$ and $3 \mathrm{~V}$, which is primarily due to the presence of pyridinic- $\mathrm{N}$ and pyrrolic-N in carbon materials [38]. The initial discharge capacity is improved with the increasing nitrogen content and the charge capacities of NCP5, NCP10, and NCP15 are significantly higher than that of NCP0. However, the initial Coulombic efficiencies of NCP0, NCP5, $\mathrm{NCP} 10, \mathrm{NCP} 15$ are $58.5 \%, 59.73 \%, 57.03 \%$, $53.47 \%$, respectively, showing a decreasing trend. This may be due to the increase of graphitic- $\mathrm{N}$ content. Because the adsorption energy of graphitic-N with $\mathrm{Li}$ is lower than the cohesive energy of Li dimmer, the increase of graphitic- $\mathrm{N}$ consumes the extra lithium ions and electrolytes during the formation of the solid-electrolyte interphase (SEI) film, leading to an increased ratio of irreversible capacity.

Fig. 4b to Fig. 4e show the first three CV curves of NCP0, NCP5, NCP10, and NCP15 at a scan rate of $0.1 \mathrm{mV} \cdot \mathrm{s}^{-1}$ between $0 \mathrm{~V}$ and $3 \mathrm{~V}$. All the $\mathrm{CV}$ curves exhibit the common characteristics of carbon materials [39]. The CV curves show a cathodic peak at $0.5 \mathrm{~V}$ in the first cycle which disappears in the following cycles. The CV curves of the second and the third cycle almost overlap. This indicates the formation of SEI films on the anode material in the first cycle. Higher current density is observed for the sample with larger nitrogen content, which may be attributed to the higher content of pyridinic$\mathrm{N}$ and pyrrolic- $\mathrm{N}$ that could generate more active sites $[22,40]$. 

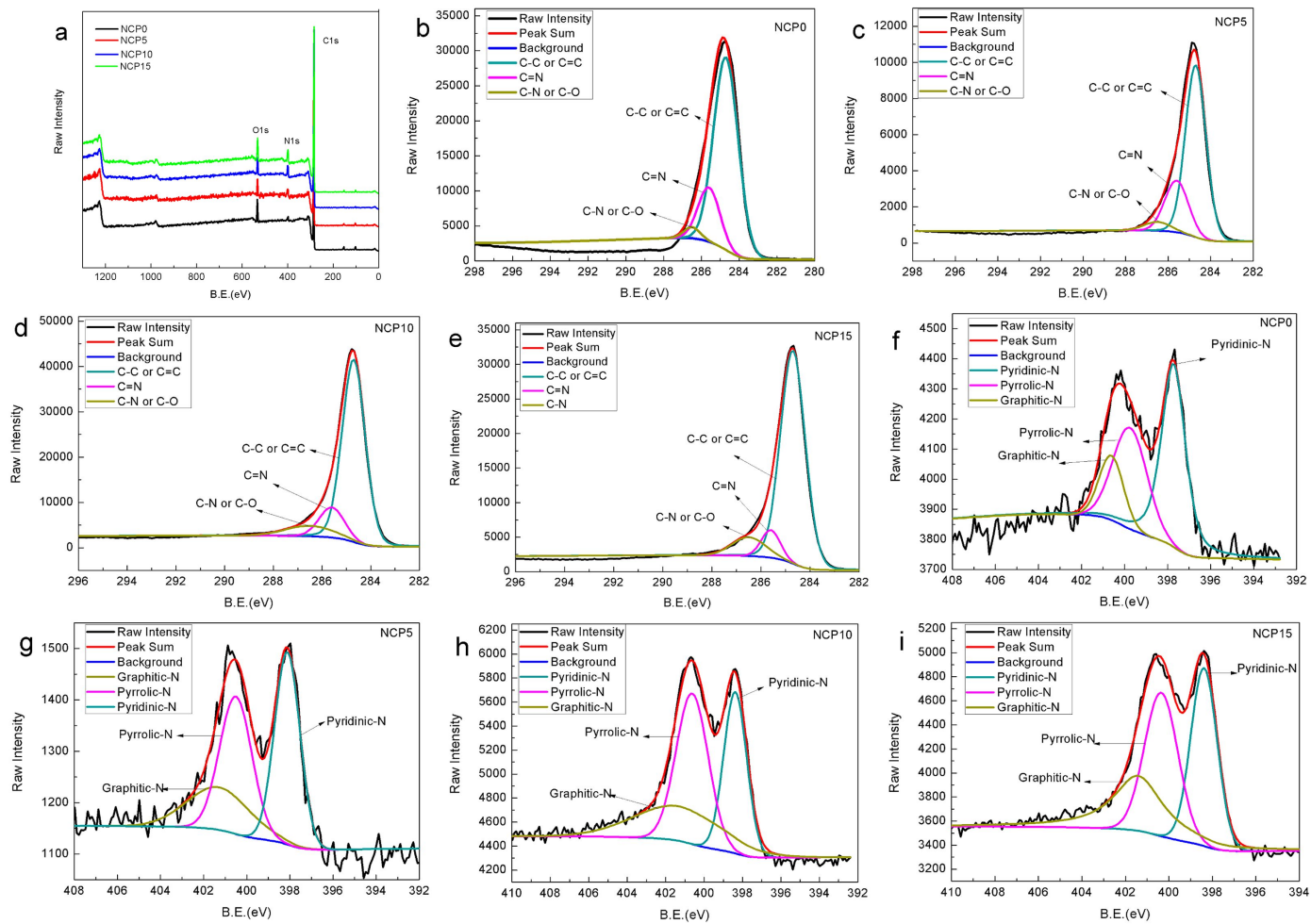

Fig. 3. XPS spectra of (a), C1s (b) to (e) N1s (f) to (i) NCP0, NCP5, NCP10, NCP15.

Table 2. Fitting results of high-resolution C1s and N1s spectra of NCP0, NCP5, NCP10 and NCP15.

\begin{tabular}{cccccc}
\hline Samples & $\begin{array}{c}\text { N content } \\
\text { [at.\%] }\end{array}$ & $\begin{array}{c}\text { pyridinic } \\
\text { nitrogen } \\
\text { [at.\%] }\end{array}$ & $\begin{array}{c}\text { pyrrolic } \\
\text { nitrogen } \\
\text { [at.\%] }\end{array}$ & $\begin{array}{c}\text { graphitic } \\
\text { nitrogen } \\
\text { [at.\%] }\end{array}$ & $\begin{array}{c}\text { graphitic nitrogen } \\
\text { as a percentage of } \\
\text { total N1s }\end{array}$ \\
\hline \hline NCP0 & 2.32 & 1.20 & 0.77 & 0.35 & 0.15 \\
NCP5 & 5.64 & 2.28 & 2.08 & 1.26 & 0.22 \\
NCP10 & 5.4 & 1.73 & 2.24 & 1.43 & 0.26 \\
NCP15 & 6.80 & 2.37 & 2.42 & 2.02 & 0.30 \\
\hline \multirow{2}{*}{ Samples } & C content & C-C/C- & C=N & C-N & \\
& [at.\%] & $\begin{array}{c}\text { H/C }=\mathrm{C} \\
\text { [at.\%] }\end{array}$ & [at.\%] & [at.\%] & \\
\hline NCP0 & 91.47 & 71.05 & 17.75 & 2.67 & \\
NCP5 & 89.59 & 63.93 & 21.58 & 4.08 & \\
NCP10 & 89.85 & 69.69 & 12.15 & 8.01 & \\
NCP15 & 87.28 & 71.96 & 6.96 & 8.36 & \\
\hline
\end{tabular}

Fig. 4f exhibits the cycle performance of all $404 \mathrm{mAh} \cdot \mathrm{g}^{-1}$, respectively. The Coulombic effisamples at a current density of $37.2 \mathrm{~mA} \cdot \mathrm{g}^{-1}$ be- ciency is above $99 \%$ for all the samples. The catween $0.005 \mathrm{~V}$ and $3 \mathrm{~V}$. The reversible capacity of pacity of the carbon materials has a rising tendency NCP0, NCP5, NCP10, and NCP15 are maintained with the increase of the ionic liquid content in the at $308 \mathrm{mAh} \cdot \mathrm{g}^{-1}, 360 \mathrm{mAh} \cdot \mathrm{g}^{-1}, 388 \mathrm{mAh} \cdot \mathrm{g}^{-1}$, and precursor, which is due to that the increased level 

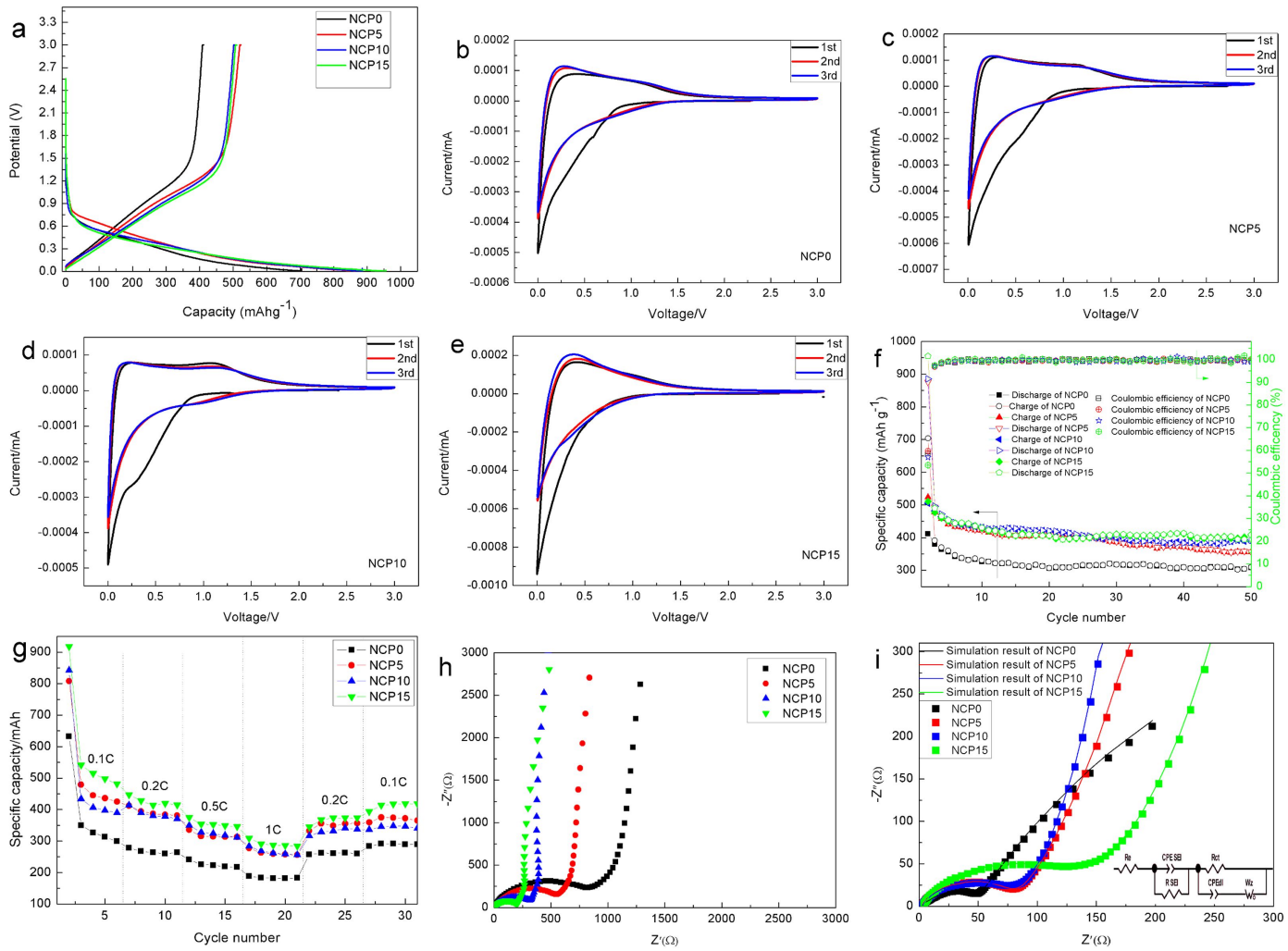

Fig. 4. Electrochemical performance of NCP0, NCP5, NCP10, NCP15: (a) galvanostatic charge-discharge profile at a current density of $37.2 \mathrm{~mA} \cdot \mathrm{g}^{-1}$; (b) to (e) the first three cycles $\mathrm{CV}$ curves ; (f) cycling performance at a current density of $37.2 \mathrm{~mA} \cdot \mathrm{g}^{-1}$; (g) rate performance at different current densities from $37.2 \mathrm{~mA} \cdot \mathrm{g}^{-1}$ to $372 \mathrm{~mA} \cdot \mathrm{g}^{-1}$; (h) to (i) Nyquist plots over the frequency range $100 \mathrm{kHz}$ to $0.01 \mathrm{~Hz}$ before cycle and after the first three CV cycles, respectively.

of pyridinic- $\mathrm{N}$ and pyrrolic- $\mathrm{N}$ creates more active sites $[3,16]$. However, the lithium storage capacity does not show significant improvement, which may be due to the increased graphitic-N content that consumes more lithium ions and electrolyte during the process of forming SEI films. This is consistent with the result of the first cycle galvanostatic charge-discharge profile. Fig. $4 \mathrm{~g}$ shows the rate performance of NCP0, NCP5, NCP10, and NCP15 as electrode material. The NCP5, NCP10, and NCP15 all show better rate performance than $\mathrm{NCP} 0$, which is also caused by higher ILs content in the precursor and consequently, a higher content of pyridinic-N and pyrrolic-N. Meanwhile, the rate performance of NCP5, NCP10, NCP15 shows the same variation trend as galvanostatic chargedischarge profile, especially in the high rate performance. The discharge capacity of NCP5, NCP10, and NCP15 are $256 \mathrm{mAh} \cdot \mathrm{g}^{-1}, 258 \mathrm{mAh} \cdot \mathrm{g}^{-1}$, and $288 \mathrm{mAh} \cdot \mathrm{g}^{-1}$, respectively. As a result, the rate performance of all samples also indicates a negative effect of graphitic-N and the positive effect of pyridinic- $\mathrm{N}$ and pyrrolic- $\mathrm{N}$ on the capacity.

In order to further understand the negative effect of graphitic-N on the storage capacity of lithium ions, the (EIS) measurements of active materials were conducted before and after the first three CV cycles of the half cell. The corresponding Nyquist plots are shown in Fig. $4 \mathrm{~h}$ and Fig. 4i, respectively. The Nyquist plots before cycling can be divided into two parts: the depressed semicircle at high and middle frequency region and a tilted straight line at low frequency region [39]. The depressed semicircle is correlated to the charge-transfer resistance and the tilted straight line is related to the diffusion resistance of 
lithium ion through the active materials [23, 36]. As seen in Fig. 4h, the charge-transfer resistance of NCP0, NCP5, NCP10 and NCP15 decreases due to the increasing of graphitic-N content. Although the increasing content of pyridinic- $\mathrm{N}$ and pyrrolic-N are detrimental to the conduction [41]. So the improved conductivity is mainly caused by the increased graphitic-N, which can form the $\pi$-conjugated aromatic carbon network in carbon crystals [37]. The Nyquist plots after cycling were analyzed by an equivalent circuit [42]. As shown in the Fig. 4i, the total resistance of electrolyte, electrode and separator are expressed by Re; the resistance and capacitance of the SEI film are represented by $\mathrm{R}_{\mathrm{SEI}}$ and $\mathrm{CPE}_{\mathrm{SEI}}$, respectively; the charge-transfer resistance is denoted by Rct [36]. The $\mathrm{R}_{\mathrm{SEI}}, \mathrm{CPE}_{\mathrm{SEI}}$ and Rct are assigned to the high and middle frequency region in the depressed semicircle of Nyquist plots. The diameter of the depressed semicircle of all samples after cycling is smaller than that before cycling, which could be attributed to the effect of N-doping [36]. By fitting the Nyquist plots after cycling with $\mathrm{Z}$ view, it is found that the $\mathrm{R}_{\mathrm{SEI}}$ are $66.34 \Omega, 90.68 \Omega$, $84.09 \Omega$, and $140.96 \Omega$, for NC0, NCP5, NCP10, and NCP15, respectively. This phenomenon may be associated with the composition of the SEI film. As a result, the rising trend of $\mathrm{R}_{\mathrm{SEI}}$ is due to that more compounds were generated during the formation process of SEI film. And the increased graphitic-N could promote the formation of SEI due to the high cohesive energy with lithium atom, which consumes more irreversible lithium ions and gradually reduces Coulombic efficiencies of NCP0, NCP5, NCP10 and NCP15 at the first galvanostatic charge-discharge cycle [43]. The results of EIS measurements also indicate that the graphitic$\mathrm{N}$ plays a negative role in the lithium storage capacity.

\section{Conclusion}

The $\mathrm{N}$-doped carbon materials have been produced using poly(acrylonitrile)-ionic liquid copolymer as carbon precursor by heating at $900{ }^{\circ} \mathrm{C}$. The copolymer was prepared using four different weight ratios of AN to ILs. The addition of ILs is an effective strategy for the regulation of nitrogen content and nitrogen configurations. Besides, the pyridinic-N and pyrrolic-N play a positive role in the improvement of lithium storage performance. On the contrary, the content of graphitic$\mathrm{N}$ and the ratio of graphitic-N to total nitrogen both show an obvious upward trend, which consumed more lithium and electrolyte, leading to a negative impact on the LIBs capacity.

\section{Acknowledgements}

The authors thank the National Natural Science Foundation of China (NFSC) (Grant No. 52064035, 51404124) and the Foundation for Innovation Groups of Basic Research in Gansu Province (No. 1606RJIA322) for financial support.

\section{References}

[1] Ji J., LIU J., LAI L., ZhaO X., Zhen Y., LiN J., ZHU Y., Ji H., Zhang L.L., RuOFF R.S., ACS Nano, 9 (2015), 8609.

[2] Pham-Cong D., Park J.S., Kim J.H., Kim J., BRAUN P.V., CHOI J.H., KIM S.J., JEONG S.Y., CHO C.R., Carbon, 111 (2017), 28.

[3] Guo W., Li X., Xu J., LiU H.K., Ma J., Dou S.X., Electrochim. Acta, 188 (2016), 414.

[4] LiU X., Zhang J., Guo S., Pinna N., J. Mater. Chem. A, 4 (2016), 1423

[5] LiU X., Wu Y., Yang Z., Pan F., Zhong X., Wang J., GU L., YU Y., J. Power Sources, 293 (2015), 799.

[6] Zhang Y., Wang Y., Meng Y., Tan G., Guo Y., XIAO D., $R S C A d v ., 6$ (2016), 98434.

[7] WANG H.-G., WANG Y., Li Y., WAN Y., DUAN Q., Carbon, 82 (2015), 116.

[8] Han S.-W., Jung D.-W., JeOng J.-H., OH E.-S., Chem. Eng. J., 254 (2014), 597.

[9] Yue H., Li F., Yang Z., Tang J., Li X., He D., Mater. Lett., 120 (2014), 39.

[10] Kim J.G., LiU F., LeE C.-W., LeE Y.-S., Im J.S., Solid State Sci., 34 (2014), 38.

[11] Sun Y., Ning G., QI C., LI J., Ma X., XU C., LI Y., ZhANG X., GAO J., Electrochim. Acta, 190 (2016), 141.

[12] Wang J., Yang Z., Pan F., Zhong X., LiU X., Gu L., YU Y., RSC Adv., 5 (2015), 55136.

[13] Selvamani V., RaVikumar R., Suryanarayanan V., Velayutham D., Gopukumar S., Electrochim. Acta, 190 (2016), 337.

[14] Khoobi A., Ghoreishi S.M., Behpour M., ShaTERIAN M., Salavati-Niasari M., Colloid. Surface. B-Biointerf., 123 (2014), 648.

[15] Ghoreishi S.M., Behpour M., Khoobi A., MASoum S., Arab. J. Chem., 10(2017), S3156.

[16] Qian C., Guo P., Zhang X., Zhao R., Wu Q., HuAn L., Shen X., Chen M., RSC Adv., 6 (2016), 93519. 
[17] Mao Y., Duan H., Xu B., Zhang L., Hu Y., Zhao C., WAng Z., Chen L., YAng Y., Energ. Environ. Sci., 5 (2012), 7950.

[18] Czerw R., Terrones M., Charlier J.-C., Blase X., Foley B., Kamalakaran R., Grobert N., TERrones H., AJAYAN P., BlaU W., arXiv preprint cond-mat/0011318, 2000).

[19] Collins J., Gourdin G., Foster M., Qu D., Carbon, 92 (2015), 193.

[20] Yang Y., Zheng F., Xia G., Lun Z., Chen Q., J. Mater. Chem. A, 3 (2015), 18657.

[21] TAN Z., Ni K., Chen G., Zeng W., TaO Z., IKraM M., Zhang Q., Wang H., Sun L., ZhU X., WU X., Ji H., Ruoff R.S., Zhu Y., Adv. Mater, 29 (2017).

[22] Zheng F., Yang Y., Chen Q., Nat. Commun., 5 (2014), 5261.

[23] Zhu J., Chen C., Lu Y., Ge Y., Jiang H., Fu K., Zhang X., Carbon, 94 (2015), 189.

[24] Jeong M.-G., Islam M., Du H.L., Lee Y.-S., Sun H.-H., Choi W., LeE J.K., Chung K.Y., JunG H.G., Electrochim. Acta, 209 (2016), 299.

[25] Wang X., Weng Q., LiU X., Wang X., TAng D.M., Tian W., Zhang C., Yi W., LiU D., Bando Y., GolBerg D., Nano Lett., 14 (2014), 1164.

[26] Shin W.H., JeOng H.M., KIM B.G., KANG J.K., ChOI J.W., Nano Lett., 12 (2012), 2283.

[27] Wang H.-G., Yuan C., Zhou R., Duan Q., Li Y., Chem. Eng. J., 316 (2017), 1004.

[28] Li Z., Xu Z., Tan X., Wang H., Holt C.M.B., Stephenson T., Olsen B.C., Mitlin D., Energ. Environ. Sci., 6 (2013), 871.

[29] Cho K.T., Lee S.B., LeE J.W., J. Phys. Chem. C, 118 (2014), 9357.

[30] Zhao Q., Fellinger T.P., Antonietti M., Yuan J., Macromol. Rapid Commun., 33 (2012), 1149.

[31] ZhaO W., LU Y., WANG J., CHEN Q., ZHOU L., JIANG J., CHEN L., Polym. Degr. Stabil., 133 (2016), 16.
[32] Zhang W., Musen L.I., J. Mater. Sci. Technol., 21 (2005), 581.

[33] Rahaman M.S.A., Ismail A.F., Mustafa A., Polym. Degr. Stabil., 92 (2007), 1421.

[34] Guanghui W., Ruiyi L., Zaijun L., Junkang L., Zhiguo G., Guangli W., Electrochim. Acta, 171 (2015), 156.

[35] Wu X., Yu X., Lin Z., Huang J., CaO L., Zhang B., Zhan Y., Meng H., Zhu Y., Zhang Y., Int. J. Hydrogen Energ., 41 (2016), 14111.

[36] Wang H., Zhang C., LiU Z., Wang L., Han P., XU H., Zhang K., Dong S., YaO J., Cui G., J. Mater. Chem., 21 (2011), 5430.

[37] Einert M., Wessel C., Badaczewski F., LeICHTweiss T., Eufinger C., JANEK J., YuAN J., Antonietti M., Smarsly B.M., Macromol. Chem. Phys., 216 (2015), 1930.

[38] Yan G., Li X., Wang Z., Guo H., Wang C., J. Power Sources, 248 (2014), 1306.

[39] Ou J., Yang L., Zhang Y., Chen L., Guo Y., XiaO D., Chinese J. Chem., 33 (2015), 1293.

[40] Ling Z., YU C., FAN X., LiU S., YAng J., Zhang M., Wang G., XiaO N., QIU J., Nanotechnology, 26 (2015), 374003.

[41] Ismagilov Z.R., Shalagina A.E., Podyacheva O.Y., ISCHENKO A.V., KiBIS L.S., BORONIN A.I., Chesalov Y.A., Kochubey D.I., Romanenko A.I., ANIKEEVA O.B., BuRYAKov T.I., TKACHEV E.N., Carbon, 47 (2009), 1922.

[42] Jin J., Shi Z.-Q., WANG C.-Y., Electrochim. Acta, 141 (2014), 302.

[43] Saravanan K.R., Kalaiselvi N., Carbon, 81 (2015), 43.

Received 2018-01-24

Accepted 2019-04-23 